\title{
CLIMATE CHANGE EFFECTS ON AQUACULTURE PRODUCTION PERFORMANCE IN MALAYSIA: AN ENVIRONMENTAL PERFORMANCE ANALYSIS
}

\author{
Rosita Hamdan \\ University of Malaysia Sarawak \\ University of Malaya \\ Azmah Othman \\ University of Malaya \\ Fatimah Kari \\ University of Malaya
}

\begin{abstract}
This study identifies the effects of climate variability as an environmental pressure on aquaculture production in Malaysia. Using Malmquist index approach, the analyses were applied to brackish-water ponds and cage aquaculture sectors in six states in Malaysia from 1993 to 2013. The Dynamic Malmquist Data Envelopment Analysis results had reflected that environmental technical change is the main factor behind the improvement of environmental performance index in pond production while the relative eco-efficiency is the major influencing factor in environmental performance index in cage aquaculture. Moreover, Pahang is the most efficient states in environmental aspects and technical support of brackish-water aquaculture ponds and cage activities, while Selangor is the least efficient state in aquaculture activities and under high climate change risks.
\end{abstract}

Keywords: Aquaculture Production; Climate Change; Environmental Performance Index; Relative Eco-Efficiency; Environmental Technical Change.

\section{INTRODUCTION}

Increased world demand on fish protein and over exploitation of fisheries have encouraged the development of aquaculture sectors, especially in developing countries within the Asia Pacific region. It has been estimated that in recent years, the world population has increased to about 7.8 billion people and due to this growth, 2.2 million metric tons of fish should be produced to fulfill the demand of fish consumption per year. The rapid development of aquaculture throughout the world and their significant contribution to the world's fish supply have increased gradually where the aquaculture contribution to total fish production increased from $23.9 \%$ in $1990,25 \%$ in $1995,40.2 \%$ in 2000 and $54.6 \%$ in 2012 . In 2006 , aquaculture

2 Corresponding author: Rosita Hamdan, Faculty of Economics and Business, University of Malaysia Sarawak, 94300 Kota Samarahan, Sarawak. E-mail: rositahamdan@gmail.com. 
has been identified as the supplier for $46 \%$ of the world's fish production with an average annual growth of $7 \%$. This performance has continuously increased to $87.5 \%$ (58.3 million tons of the world's food fish) in 2012 (World Bank, 2010; Food and Agricultural Organization [FAO], 2014).

Malaysia's aquaculture sector development had started since the 1920's. It started with freshwater aquaculture and then brackish-water aquaculture in the late 1930s. Cage aquaculture sector had started in Peninsular Malaysia circa 1970s (Tan, 1998). Meanwhile, in Sabah and Sarawak (East Malaysia), the aquaculture sector had only started to grow in the early 1990s. Currently, Malaysia's aquaculture comprises of three common practices which are fresh water, brackish-water and marine aquaculture.

The important role of the aquaculture sector was emphasized in the Third National Agriculture Policy (1998-2008) and recently, in the National Agro-Food Policy (2011-2020), as a major area of concentration to enhance the competitiveness of agriculture sector in Malaysia. This sector is identified as one of the important drivers of economic activities under the National Key Economics Area (NKEA). The contribution of aquaculture sector to Malaysia's GDP showed positive improvement within years, where it had contributed 0.283 in production value in percent of GDP, in 2003 (Lungren, Staples, Funge-Smith \& Clausen, 2006), increased to $0.367 \%$ in 2004 (Sugiyama, Staples, \& Funge-Smith, 2004) and 0.3\% in 2006 (Lymer, FungeSmith, Clausen \& Miao, 2008). In terms of percentage share of GDP for agriculture sector, the contribution of aquaculture sector consistently grossed from $4.5 \%$ in 2006 to $6.7 \%$ in 2010 (Department of Statistic [DOS], 2011). In 2013, the aquaculture sector had contributed to $5 \%$ added value of the Malaysia Agriculture sub-sectors (Malaysia Productivity Corporation [MPC], 2014).

The rapid growth of aquaculture production in Malaysia has been due to huge allocations of physical and financial facilities by the government in various aquaculture development projects, especially in aquaculture industrial zone projects. Thus, the aquaculture sector in Malaysia is transformed into a more technological activity driven with high market contribution. The underlying reasons are due to the important contribution of aquaculture sector in increasing the national food production, to resolve insufficient marine fishery landings, and exploitation of marine fish (Ministry of Finance [MOF], 2003; Ministry of Finance [MOF], 2011).

With respect to socio-economic, aquaculture could improve food supplies, employments, and income. There are 1,966 brackish-water cages and 984 brackish-water pond entrepreneurs in Malaysia as of 2013. The brackish-water aquaculture projects covered 2,861,068.89 m2 of land used for the cages and 6903.04 hectare of land used for the ponds. Aquaculture activities have helped alleviate poverty especially in rural areas and upgraded the livelihoods of coastal communities like fishermen in China and Indonesia. Aquaculture activities assist the livelihoods of the poor by providing nutritious foods, employment and generate income (Edwards, 2000) through various down-stream to up-stream activities, which include harvesting, processing, and marketing (Tan, 1998). The Malaysian government had launched several projects to help small-scale, low-capital farmers in enhancing their production and to reduce poverty among the farmers through programs such as Azam Tani and Smallholder 
Assistance Scheme. The development of aquaculture activities in rural areas has benefitted farmers and nearby communities through allocation and accessibility of infrastructures such as electricity, communication, and road access that help to improve the quality of life (Othman, 2006).

Aquaculture activities in Malaysia are divided into large, medium, and small scaled production. The categories are indicated from monthly and annual volume of production yields. In earlier years of aquaculture operation activities in Malaysia, most farmers operated small-scale aquaculture farms that are meant for self-consumption, whereby only the excess are sold in the market. They were vulnerable to production risks as they operated in open water sources accessed using traditional techniques and have lack of knowledge on operating high technology farming systems. Besides, they had limited access to the supply of seeds and less institutional supports to further develop their farming activities (Edwards, 2000). Lack of sustainability and reliable aquaculture were among the major weaknesses of this sector that affected towards losses and reflected poor management during that time.

The past few years had shown that the aquaculture sector is developing rapidly with largescale operators (modern equipment and technologies) contributing towards the industry. Under NKEA, the rising of capital investment, research and development (R\&D) by the government and private stakeholders in this sector had contributed to positive growth of the aquaculture industry. High impact projects in the Aquaculture Industrial Zone are also implemented. There are 31 potential Aquaculture Industrial Zones in Malaysia located in Perak, Melaka, Pahang, Terengganu, Sabah, and Sarawak. Since its establishment, the aquaculture sector has been transformed from traditionally a small-scale production based sector into a large scale agribusiness industry.

In order to encourage large-scale aquaculture activities, the government promoted the integrated cage farming entrepreneurs under EPP4 projects. The adoption of modern technology usage for modern agriculture practices by the aquaculture farmers had contributed to positive performance of this sector (MPC, 2014). The type of technology used in aquaculture is simple such that it includes small modifications of previous technologies that are able to enhance the growth and survival rates of aquaculture species. The technologies in aquaculture activities involve different aspects of aquaculture techniques, systems, facilities, engineering, feeds technology, and biotechnology (FAO, 2014). The role of fisheries research centers and fisheries institutes in aquaculture research and development has also contributed to the development of apt aquaculture technologies and good aquaculture management in Malaysia.

Hence, the environmental and social aspects have significant importance in ensuring sustainable and safe aquaculture production (Anon, 2003). Realizing the importance of sustainable aquaculture practices and food production safety, the Malaysian government had launched the Malaysian Good Agricultural Practices (MyGAP) in 2013, which serves as a rebrand to the former exercises of the Malaysian Farm Certification Scheme for Good Agricultural Practices (SALM), Livestock Farm Practices Scheme (SALT), and Malaysian Aquaculture Farm Certification Scheme (SPLAM). 


\section{AQUACULTURE SECTOR AND CLIMATE CHANGE RISK}

Climate change is a worldwide production risk and a major threat to sustainability in the aquaculture sector. Sustainable aquaculture production is determined by environmental factors such as that a suitable atmosphere for aquaculture activities will increase the survival, growth, and reproduction of fish (Sungan, 2002). The concerns about environmental externalities and consequences related to sustainability of aquaculture production have risen due to the remarkable contribution of this sector towards economic growth (Tisdell \& Leung, 1999). The productivity and profitability levels of aquaculture production depend on direct positive or indirect negative effects of climate change on aquaculture natural resources such as land, water, seeds, feeds, and energy (Oguntuga, Adesina, \& Akinwole, 2009).

Based on the social-ecology system concept, environment, aquaculture, and socio-economics interact and are dependent on each other. Thus, the risks of climate change ranged from exposure to people and property and vulnerability of physical, social, economic, and environmental factors or processes that grow in aquaculture community to the impact of hazards (Westlund, Poulain, Bage, \& Anrooy, 2007). Climate change is an involuntary risk that creates vulnerability on the socio-economic development and raises stress especially on food demand and supply and also on the income level of the farmers (Thomas \& Callan, 2007). The impacts of climate change on bio-physical and community livelihood have strong connection with each other, where they are known as the exposure unit to vulnerability of climate change.

Climate change is a natural climatic event that influences the quality and quantity of aquaculture production (Beach \& Viator, 2008). The impacts on aquaculture production due to this change differ depending on aspects such as its region, aquaculture practice systems, space, time, size, and changeability (De Silva \& Soto, 2009). According to Howden, Soussana, Tubiello, Chhetri, Dunlop, \& Meinke (2007), climate variability affects the fluctuation of fish stocks that are important to the fishing community. Biophysical factors such as climatic change and extreme weather affects the sustainable growth of the aquaculture sector (Tisdell \& Leung, 1999; De Silva, 2007).

The drivers of climate change that threatens aquaculture activities are temperature-pressure, oxygen demand and decreased $\mathrm{pH}$, water supply variation and uncertainty, severe climatic events, regularity of disease, virus and toxic outbreaks, sea level rise, and the uncertainty of captured fish supply for aquaculture feeds (Handisyde, Ross, Badjeck, \& Allison, 2006; Brander, 2007; Ficke, Myrick, \& Hansen, 2007). Fluctuation of climate events such as changes in water temperature, annual precipitation, water stratification and the shift of raining and dry seasons all changes the physiological, ecological, and operational aspects of aquaculture activities (Handisyde et al., 2006). Changes in temperature and precipitation are the major causes of failure to pond aquaculture production and usually trailed with drought and flood seasons. These events have resulted in water stratification that harms cultured species especially in shrimp production. Moreover, climate change also causes disease outbreaks (Siwar, Alam, Murad and Al-Amin, 2009; Handisyde et al., 2006) to fishes and shrimps in all stages of its growth. 
Extreme climate change causes diminishing development growth, as well as destroys lives and livelihood. Climate change puts pressure on the demographic which also changes the market as results of hazards. Climate change worsens natural resources, productive assets, information, and technology disparity; these impact the poor and marginalized groups that rely on aquaculture activities (WorldFish, 2009). Extreme weather causes farms to incur operational problems such as damage and wreckage of physical structures, productive assets and infrastructures for aquaculture activities, which lead to major escape and a decreased volume of production (Schjolden, 2004; Badjeck, Allison, Halls, \& Dulvy, 2010). In developing countries such as those in Asia, most rural people are dependent on the fishery sector. The occurrence of climate change negatively affects the interaction of aquaculture with environment and also the livelihood of indigent farmers. Climate change risks often increase production costs, thus making technology unaffordable and raise the capital needs (Kamaruddin \& Siwar, 2008) for efficient farm management (Sulit, Aldon, Tendencia, Ortiz, Alayon, \& Ledesma, 2005). The aquaculture activities are usually conducted in low intensity operations by small-family owned practices. Small scaled farmers are unable to survive in this sector due to increasing cost of production and lack of support systems to cover the production from the impacts of production risks. The farmers' failure in production and decline in food production lead to the problem of famine and poverty traps because of permanent losses of humans and physical capital (Heltberg, Siegel, \& Jorgensen, 2009).

The negative impacts of climate change on aquaculture sector have been studied in few Southeast Asian countries. Cambodia communities that depend on fisheries sector had suffered from the impacts of climate change due to poverty, marginalization, and lack of alternative incomes that make them unable to cope with the problems (Baran, Schwartz, \& Kura, 2009). Meanwhile, in Vietnam, the Hoang Bo and Xuan Thuy districts have verified that the storm surges, sea level rise, high waves, and strong winds cause severe damages and losses to aquaculture production and increase inequality to the communities that are dependent on the sector (Kelly \& Adger, 1999). The frequent flood events had caused losses to a huge number of fishes and shrimps productions in Red River Delta, Central Region, and Mekong Delta in Vietnam (Asian Development Bank [ADB], 2009). Disease and virus outbreaks had also decreased the profits to shrimp aquaculture activities in Thailand (Flaherty, Vandergeest, \& Miller, 1999). Magawata \& Ipinjolu (2014) highlighted the important aspect that need to be tackled in adapting to climate change and mitigation measures on the fisheries and aquaculture sector in terms of management improvement, aquatic ecosystems reliability, threats and opportunities on food and livelihoods security feedbacks and also in aiding the reduction of greenhouse effects caused by the sector.

A general study on the environmental risk of the aquaculture sector in Malaysia indicated that the risks have promoted social conflict among aquaculture producers in Malaysia due to competition between farmers to acquire the natural resources for production (Kamaruddin, Siwar, Jaarfar \& Mokhtar, 2008). The effects of climate change on the aquaculture sector have often been experienced by Malaysia based on the cases reported in Table 1. 
Table 1: Climate change risk cases on aquaculture sector in Malaysia.

\begin{tabular}{|c|c|c|}
\hline Climate Change Drivers & Year & Place / States \\
\hline Water intrusion, water deterioration and White Spot Disease ${ }^{1}$ & 1992 & Penang \\
\hline Drought (El Nino Southern Oscillation or ENSO) ${ }^{2}$ & 1997 & $\begin{array}{c}\text { Selangor, Sabah, and } \\
\text { Sarawak }\end{array}$ \\
\hline Floods and water stratification ${ }^{3}$ & 2008 & Sungai Semerak, Kelantan \\
\hline Drought $(\mathrm{ENSO})^{4}$ & 2009 & All states \\
\hline Disease outbreaks (Streptococcus) $)^{5}$ & 2010 & $\begin{array}{c}\text { All states in Peninsular } \\
\text { Malaysia }\end{array}$ \\
\hline
\end{tabular}

Sources: ${ }^{1}$ Hambal, Arshad \& Yahaya (1994); ${ }^{2}$ Sulong (2008); ${ }^{3}$ Mustafa (2007); ${ }^{4}$ Farabi (2009); ${ }^{5}$ MOF (2011).

Studies concerning environmental consequences on aquaculture production sustainability in Malaysia have risen quite significantly. However, only a few studies had focused on the impacts of climate change on the aquaculture sector. A recent study by Idris, Azman, D'Silva, Man, \& Shaffril (2014), conducted in selected districts in Pahang, Negeri Sembilan, Kedah, and Terengganu, indicated that the main climate threats to brackish-water cage activities are temperature rise, heavy rainfall, flood, and water currents that caused sediments and wastes flows from nearby industrial and agricultural areas pollute the aquaculture area, hence causing disease infections, fish deaths, and damaged cages. A previous study concentrating on the social science context of environmental issues of aquaculture development had been conducted by Hambal et al. (1994) and Kamaruddin et al. (2008). As climate change became a crucial problem for the aquaculture sector, together with the limited literature on climate change impacts on aquaculture sector in Malaysia, this study is intended to address this gap by contributing to the knowledge in aquaculture studies, particularly in Malaysia. Instead of identifying the impact factors of climate change to aquaculture descriptively, this study attempts to address the quantitative empirical findings of the performance index of Malaysia's corridor of aquaculture production based on eco-efficiency aspects and comparisons on the performance of aquaculture that have been influenced by climate change risks. Research indicating the indices of climate change in local and cross countries are useful in identifying effective mitigation and adaptation strategies (Magawata \& Ipinjolu, 2014). The eco-efficiency measurement is the intermediation that helps in improving sustainability of aquaculture production (Gomez-Limon, Picazo-Tadeo, \& Reig-Martinez, 2012). The environmental efficiency evaluation would help in the recommendation of new policies as well as enhancing the current environmental policies (Lansink \& Wall, 2014).

This study generally attempts to evaluate the performance of aquaculture production under the environmental pressure of climate change. Using environmental performance index analysis, this study concentrates on achieving the following objectives;

1) To identify the environmental performance index of the aquaculture sector.

2) To identify the change in the relative eco-efficiency of the aquaculture sector.

3) To identify the change in the technical progress of the aquaculture sector. 
Following this section, the methodology section gives the main insight on the methodology used, data and variables in the analyses, followed by a section on the results and discussion that presents the main findings and policy implications and finally, the conclusions and policy recommendations.

\section{METHODOLOGY}

\subsection{Climate change and aquaculture eco-efficiency}

In past agriculture sector performance studies, the efficiency of an agriculture sector or farms was measured by using economic and socio-economic factors. Due to the importance of environmental factors towards the agriculture sector, several studies had combined these factors with environmental factors and presented the eco-efficiency concepts. In those studies, the environmental factors were presented by pollution factors, which are known as environmental pressure.

Past literatures on eco-efficiency were mostly focused on other agriculture sub-sectors that are land based and industrial production systems (Ytrestoyl, Aas, Berge, Hatlen, Sorenson, Rutler et al., 2011). Only a few studies had concentrated on the eco-efficiency in fisheries sector as well as in aquaculture. The studies on the efficiency of fisheries sub-sector were covered by Dupont, Grafton, Kirley, \& Squires (2002); Tingley, Pascoe, \& Mardle (2003); Pascoe \& Herrero (2004); Tingley, Pascoe, \& Coglan (2005); Oliveira, Gaspar, Paixão, \& Camanho (2009) and Vazquez-Rowe \& Tyedmers (2013). More recent studies on Malaysia's aquaculture industry performance through technical efficiency evaluation had been done by Mustapha, Aziz and Hashim (2013). Using total freshwater aquaculture production as the output and pond area and number of culturists as the inputs, this study measures the technical efficiency of the freshwater aquaculture industry to indicate that the technical and finance assistance, fair distribution of wealth and a state's economic development level would improve the aquaculture industry in Malaysia. Furthermore, this study attempts to measure the eco-efficiency in the case where climate change impacts the aquaculture sector as environmental pressure in order to diversify the previous concentrations of environmental pressure on pollution factors. This study is also carried out to add to the relevance of an eco-efficiency analysis in aquaculture production since there are only a limited number of studies done in this area.

Following the study by Kuosmanen \& Kortelainen (2005) and using a non-parametric technique of efficiency analysis, DEA, eco-efficiency is formulated as a ratio between economic value added and measure of environmental (bio-physical factors) pressure. Linking eco-efficiency concept with the aquaculture sector and climate change, the eco-efficiency is generally defined as the capability of an aquaculture sector to produce their products using natural resources as minimum as possible, to adjust to the climate change pressures such as temperature and rainfall variability as well as to reduce wastes and pollution with increasing impacts to climate change. On the other hand, eco-efficiency is a ratio or an environmental index of economic value of aquaculture products to environmental pressure added (Kortelainen, 2008; Lansink \& Wall, 2014). The environmental performance with larger ratio values is considered as having better environmental performance and this achievement is practical in macro level aquaculture sector as compared to micro level (Huppes \& Ishikawa, 2005). 
The eco-efficiency concept aims to obtain economic results using minimum natural resources and minimize the possible environmental degradation which may increase due to environmental pressures such as climate change and the effects of aquaculture farming system and management (Gomez-Limon et al., 2012). If the value of production maintained or increased while the negative environmental impacts decreased, the eco-efficiency will progress. The advantages of the eco-efficiency progress are the ability to reduce environmental pressures in the most cost effective way and also in helping to adjust the previous policies that restrict the level of economic activity into new policies with improvements in eco-efficiency (Gomez-Limon et al., 2012). Moreover, the application of eco-efficiency needs to be used in economic value production efficiency studies as it will expand and widen the scope of previous studies that were more concerned on pollution as the environmental indicators in production than climate change problems as the environmental pressure to production. In acknowledging the findings on the role of pollution reduction in increasing efficiency and cutting costs (Picazo-Tadeo \& Prior, 2009), it is expected that a reduction in climate change impacts will help to increase the eco-efficiency in aquaculture production.

In this study, a Malmquist Data Envelopment Analysis was applied in identifying Malaysia's aquaculture production performance index with the existence of global environmental problems known as the climate change pressure. The advantage of using the Dynamic Malmquist Data Envelopment Analysis is that this analysis can be used with the inclusion of different units or less economic meaning of variables that are later enveloped or decomposed into relevant economic foundations to explain the environmental changes effects on aquaculture production efficiency. This study considers different categories of brackish-water aquaculture systems (pond aquaculture and cage aquaculture) where the eco-efficiency value will be evaluated. The assumptions about farm behavior, production functional form or efficiency distribution are excluded from the analysis but all farms are assumed to own the same production technology at a given period (Hoang \& Coelli, 2011).

\subsection{Malmquist Data Envelopment Analyses}

The Dynamic Malmquist Index Data Envelopment Analysis was employed to elucidate the sources of environmental changes and technical progress of farms. The Malmquist index of data envelopment analysis has the advantage of performing although with no information on prices or even with available prices that have less economic value. The dynamic eco-efficiency enables the analysis of technical progress and clarifies sources of environmental changes (Serrao, 2008), where the analysis allows for the decomposition of productivity changes into significant sources of environmental changes. In general, the traditional Malmquist productivity index can be written as;

$$
m_{0}\left(y_{t+1}, x_{t+1}, Y_{t}, x_{t}\right)=T F P C H=E F F C H \times T E C H C H
$$

The traditional Malmquist productivity index analyzes the changes of economic efficiency that may be influenced by technical changes from the differences in production technology and efficiency change as results of the production efficiency change over the period of time (Ramli, 2013). With respect to the objective of this study, the definition of Malmquist DEA 
follows the definition given by Kortelainen (2008). Thus, the Malmquist productivity index does not reveal total factor productivity (TFP) but has been utilized to focus on environmental performance measurements. In environmental performance measurements, good output index is the ratio of output distance functions while bad output index is the ratio of input distance functions. Thus according to Kortelainen, Malmquist productivity index is also the ratio of input distance functions.

The estimation of environmental performance index (EPI) is obtained from the decomposition of two components, which are relative eco-efficiency change (REE) and environmental technical change (ENVTECH). The environmental performance index will determine whether the environmental performance of a production unit has improved or not but does not disclose the reasons or sources of the changes (Serrao, 2008). Malmquist productivity index measures the EPI level between two data points by calculating the ratio of distances for each data point relative to a common technology. The advantage of measuring EPI is that results are invariant where the measurement units of input and output are disregarded. The measurement outcome is in geometric average. The Malmquist environmental performance index as the input-oriented Malmquist productivity index can be specified as (Fare, Grosskopf, Norris, \& Zhang, 1994);

$$
E P I_{\alpha}(t-1, t)=\left(\frac{E E_{\alpha}\left(p^{t}, i^{t}, t-1\right)}{E E_{\alpha}\left(p^{t-1}, i^{t-1}, t-1\right)} \times \frac{E E_{\alpha}\left(p^{t}, i^{t}, t\right)}{E E_{\alpha}\left(p^{t-1}, i^{t-1}, t\right)}\right)^{1 / 2}
$$

$t=2, \ldots \ldots, T$.

Or, the Malmquist environmental performance index can also be simplified to;

$$
E P I_{\alpha}(t-1, t)=\Delta R E E_{\alpha}(t-1, t) \times \triangle E N V T E C H_{\alpha}^{t, t-1}, t=2, \ldots \ldots, T .
$$

Improvement in environmental performance may result from higher relative eco-efficiency, progress of environmental technology or both. $E E_{\alpha}\left(p^{t-1}, i^{t-1}, t\right)$ represents the distance from period $t-1$ observation to period $t$ technology and is known as the Environmental Performance Index (EPI). Environmental performance index is positive if a value is greater than one from the period $t-1$ to period $t$ and vice versa. The decomposition of environmental performance changes according to Nishimizu \& Page (1982) and Fare et al. (1994) and is as follows;

$$
\text { Relative eco- efficiency change }=\Delta E E_{\alpha}(t-1, t)=\frac{E E_{\alpha}\left(p^{t}, i^{t}, t\right)}{E E_{\alpha}\left(p^{t-1}, i^{t-1}, t-1\right)}
$$


Relative eco-efficiency is a ratio of value added and environmental damage index. This ratio identifies the level of catching up or how a production unit's environmental performance has changed relative to its benchmarks. If the relative eco-efficiency change value is more or equal to one, the unit has caught up to its benchmark in period $t$ as compared to its benchmark in $t-1$ and vice versa.

Environmental Technical change $=\Delta E N V T E C H_{\alpha}^{(t, t-1)}=\left(\frac{E E_{\alpha}\left(p^{t-1}, i^{t-1}, t-1\right)}{E E_{\alpha}\left(p^{t-1}, i^{t-1}, t\right)} \times \frac{E E_{\alpha}\left(p^{t}, i^{t}, t-1\right)}{E E_{\alpha}\left(p^{t}, i^{t}, t\right)}\right)^{1 / 2}$

Environmental technical change means that the production unit's environmental performance has either improved, becomes stagnant or deteriorates in applying the best practice technology and innovation. The positive indices value (greater than one) attributes towards technical progress whereas negative value (indices less than one) indicates technical regress of the production unit. Kortelainen (2008) advocated that in this analysis there is no specific reference on the change of technical change either in period t or $\mathrm{t}-1$ from the observation. The measurement of environmental technical change is based on the geometric average of the analysis. The value shows whether good or worse improvements have been shown by the aquaculture production due to the contribution of the best current practiced technology or innovation or even environmental regulatory that is related to the industry.

\subsection{Data and variables}

This study will indicate the environmental performance of aquaculture production in brackishwater aquaculture systems as the result of the impact of climate change. Although there are many types of culture systems, this study will only indicate the performance for cage systems and pond systems. Ponds and cages have been selected due to direct exposures to the changes in climate or environmental factors on their ecosystem. This study uses a balanced panel data of 21 years (from 1993 to 2013) from the six states in Malaysia. The production units (states) or also known as decision making units (DMU) in common DEA is selected based on the regional corridors in Malaysia. These states are Perak (northern region), Pahang (east coast region), Selangor (central region) and Johor (southern region) that represent peninsular Malaysia (West Malaysia). East Malaysia (Borneo Island) is represented by Sabah (Sabah Development Corridor) and Sarawak (Sarawak Corridor of Renewable Energy). These states have been chosen because the states perform highest in aquaculture production in its regional areas. Secondly, in terms of institutional role, the aquaculture production in Sarawak is monitored and controlled by the Department of Agriculture while in Sabah and Peninsular Malaysia, by the Department of Fisheries. Thirdly, these states may have differences in geographical locations, patterns of climate and environmental features that may have a great influence to sustainable aquaculture activities.

Production units in this study are the six states. An input-oriented DEA method is used to identify factors that contributed to the production risk. Inputs are comprised of environmental factors (climate change pressure) and farm sizes as the denominator while value added is the output and also numerator to the eco-efficiency measurement. The modelling of the 
environmental factors and farm acreage as inputs is based on the argument that reducing and adapting to the impact of climate change must be accompanied by either a decreasing or maintaining of the volume of production in order to cope with the production risks and hence increases the value added of the sector. According to Coelli (1996), input oriented can be used to identify inefficient technical values in production performance. In this study, retail value (value added in $\mathrm{RM}$ ) is the output of the analysis. The inputs comprises of mean annual maximum weather temperature $\left({ }^{\circ} \mathrm{C}\right)$, mean annual minimum weather temperature $\left({ }^{0} \mathrm{C}\right)$, mean annual rainfall ( $\mathrm{mm} /$ day), percentage of mean annual relative humidity $(\%)$, and aquaculture farm size (ha for ponds and $\mathrm{mm}^{2}$ for cages). Data on retail value and farm size are acquired from the Annual Fisheries Statistics, the Department of Fisheries for production data while the environment data are from the Yearbook of Statistics by the Department of Statistics, Malaysia. Although the terms inputs and outputs are still used to present the variables of the study, their quantities are not as important as in the traditional productivity efficiency studies. The eco-efficiency analysis is concerned about the society-level economic efficiency analysis. Thus, the value added can be presented by the gross Margin, net profit or net income (GomezLimon et al., 2012) or revenue (Hoang \& Coelli, 2011) to present the economic value in the eco-efficiency analysis. According to Picazo-Tadeo, Gmez-Limon, \& Reig-Martinez (2011), the value added can be directly and indirectly calculated using data on prices and quantities of outputs and intermediate inputs. However, this study used retail value to present value added and the cost of labor and capital inputs are not deducted from the value because they represent income (wages and rents) for the society. Moreover, the environmental factors used physical value and not monetary units since these factors do not typically have price or other unambiguous values (Hoang \& Coelli, 2011). The environmental pressure is presented by the biophysical factors of climate change.

\section{RESULTS AND DISCUSSION}

The Environmental Performance Index (EPI) of the six states in Malaysia of brackish-water aquaculture ponds and cage activities were based on 20 observation scores from 1993 to 2013. Figures 1 and 2 illustrate the changes in EPI for the respective states. The summary of annual means of EPI and its composition are illustrated in Figure 3. The significant contribution of Relative Eco-Efficiency (REE) change and Environmental Technical (ENVTECH) change to the EPI achievement were evaluated based on the scores achieved in those components in respective years and states. Although this study acknowledges the importance of production factors such as capital, labor, and other inputs as the determinants of aquaculture production efficiency, this analysis only considers the biophysical aspects where physical and ecological stressors are regarded as factors of aquaculture production. The component index will indicate whether the aquaculture activities are resilient to climate risks through REE components; and whether or not current technologies, innovations, related policies have improved the aquaculture growth through the ENVTECH index evaluation. The understanding on complexity of climate change risks in aquaculture development can be enhanced through REE, EPI, and ENVTECH component information (Ytrestoyl et al., 2011). The interpretation of these indexes will indirectly provide information on economic, environmental, and social conditions under the changing climate (Miola \& Simonet, 2014). 


\subsection{Brackish-water ponds' EPI}

The EPI results revealed that Perak, Johor, Sabah, and Sarawak are among the efficient states as these states had achieved efficient scores for 13 times throughout the observation. The least efficient state with pond aquaculture activities is Selangor with only 8 times of efficient EPI scores over the years. All states had obtained efficient EPI scores (more or equal to 1) in the years 1998, 2005, and 2008. Consecutively, almost all states had obtained inefficient EPI scores except for Selangor in 2004, Sarawak in 2011, and Sabah in 2013. The highest score is a $23.2 \%$ increase in EPI and was obtained by Sabah in 2006. Sarawak and Johor achieved the least efficient scores that showed a 13.5\% decrease in EPI in 1996 and 2011 respectively.

The positive EPI (positive efficiencies) in 1998 and 2008 were due to the efficient index achieved by all the states in both REE and ENVTECH in the respective years. The combinations of REE and ENVTECH results for all states also contributed to the overall efficiency of EPI in 2005 except for Sabah where only the ENVTECH progress had influenced the positive results of EPI. The overall efficient scores of REE in all states were achieved in 1995, 2000, 2004, and 2007; while in ENVTECH, the overall positive efficient scores of the states were achieved in 1994 and 2009. In the occurrence of climate variability risks, the technology regress could be due to the lack of innovation that causes the EPI decrease. This can be seen in 2004, 2010, and especially in 2011. The least efficient year for REE in all the states was in 1999 where four out of six states were found inefficient. The occurrence of monsoon flood hazards in Malaysia from November 1998 to March 1999 was due to heavy rains, which might had affected the aquaculture activities in some parts of Sabah and Sarawak as these states were prone to said hazards in that particular year (Mohd, Alias \& Daud, 2006). The highest score for efficiency in REE was achieved by Pahang with a 14.9\% REE increase in 1998 and the highest inefficiency scores for REE in pond aquaculture sector was seen in Sarawak in 2009 with a decrement of $14.4 \%$. The occurrences of El Nino phenomena in 1999 had affected the drought season in Malaysia and reduced the production in most of the agriculture sector including the aquaculture sub-sectors (Farabi, 2009). The high progress of technical and innovation is seen in Sarawak

Figure 1: Annual change in environmental performance index of brackish-water ponds, $1993-2013$

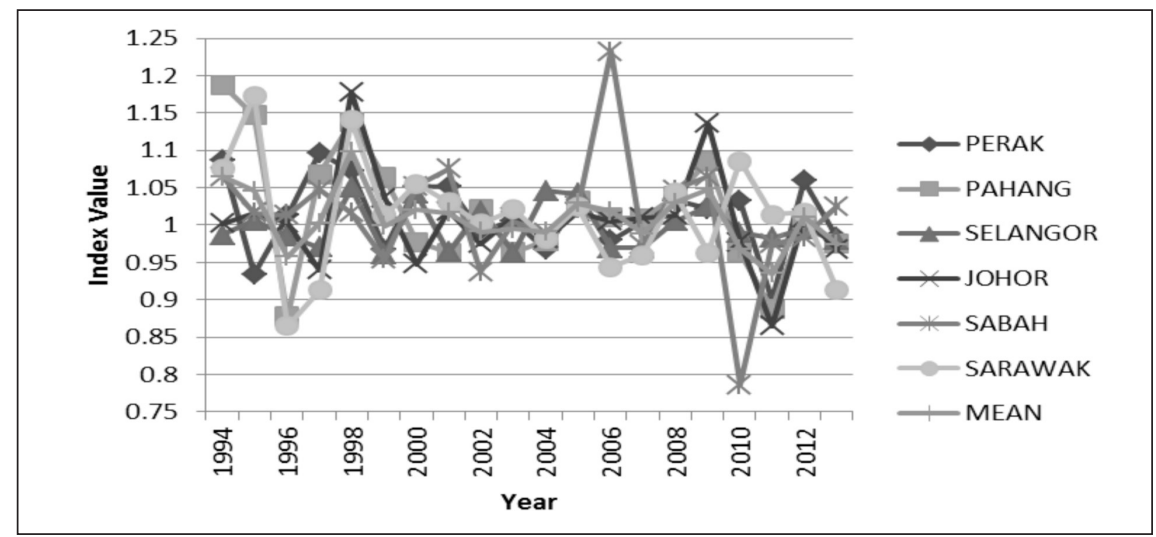


in 1995 that achieved a 17.3\% positive increase in ENVTECH. The lack of technological and innovation can be seen in Sabah in 2010 as this state decreased 19.6\% from the efficient level.

\subsection{Brackish-water cages' EPI}

The EPI of the 6 states with brackish-water aquaculture cages in Malaysia showed a decrease in the index value as compared to pond aquaculture (Figure 2). None of the states achieved total EPI efficiency. The best observation for brackish-water cage aquaculture activities within 20 years was shown in 2000, 2005, and 2009. However, Johor had an inefficient score in 2000 and Pahang in 2005 and 2009. Nevertheless, the full efficient scores of ENVTECH in 2003 also affected towards the positive scores of EPI in the same year except for Perak and Sabah, which had much lower scores in REE thus affecting the EPI more. The strong and significant technical progress (ENVTECH) in cage aquaculture was in the year 2000 where almost all states are efficient except Johor. The low REE scores did not affect any of the state EPIs in this year.

The positive EPI results in 2005 and 2009 were due to the overall efficient scores in ENVTECH. Technology and innovation has progressed well in these years for all the states. The worst years for EPI of brackish-water cage aquaculture were in 1999, 2001, 2010, and 2011, showing that four out of six states were inefficient in their EPI index. The overall inefficient scores of ENVTECH that were obtained by the states significantly affected the states' EPI in 2001 and 2010. However, the inefficient ENVTECH scores did not affect the states so much in 1995 and 2002 as the effects were moderated by the good REE scores of the states. The climate change in 1995 and 2002 were at a tolerable level and did not affect the aquaculture ecosystem much as there was no decreasing of aquaculture production. Pahang and Selangor were the least efficient states in their EPI over the years where they achieved half of the score frequency or 10 times lesser than 1 scores in their EPI index. The most efficient state based on the EPI index frequency was Sarawak that achieved efficient scores for 13 times in EPI over the years.

Figure 2: Annual changes in environmental performance of brackish-water cages, $1993-2013$

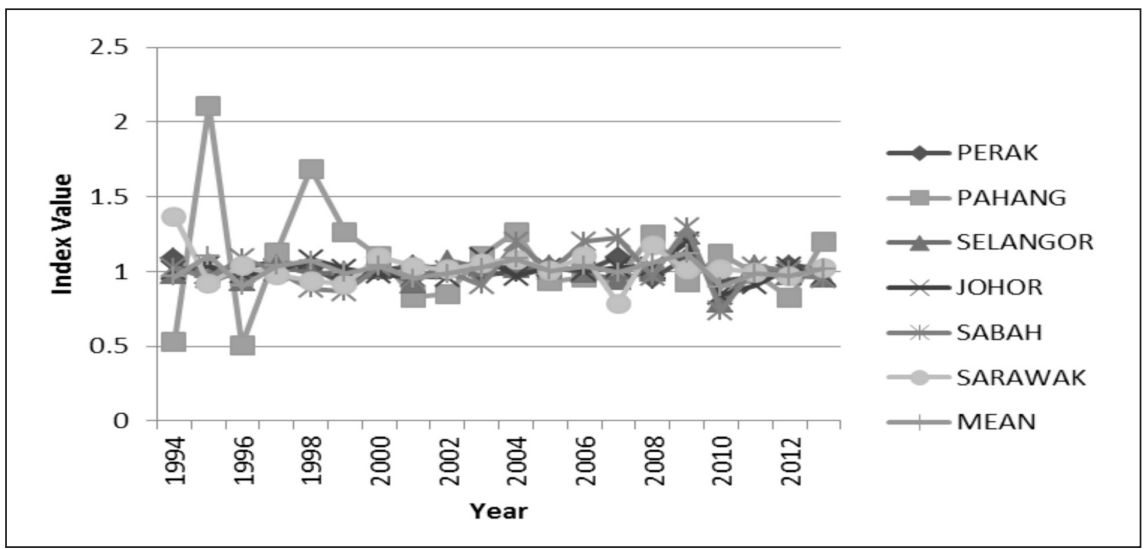


By comparing REE and ENVTECH of brackish-water cages, this analysis revealed that environmental progress plays a great role in determining the EPI performance of the states. The decomposition EPI results showed that brackish-water cage aquaculture in Malaysia is more dependent on the REE factors (conducive environmental or ecosystem for aquaculture activities) as compared to the ENVTECH components. The reason behind this is because the cage activities operate in open water systems or at the riverbank as compared to pond aquaculture that only operates inland. Therefore, the brackish-water cages aquaculture were most probably faced with higher risks and more vulnerable towards environmental risks such as massive water current, water eutrophication, salinity, and pollution.

The brackish-water aquaculture activities in all the states were completely efficient in terms of their REE in 1997, 1998 and 2013. The overall efficient scores in REE were unable to lead to an overall efficient score for EPI in those years due to the effects of inefficient scores in technical progress in the cage activities. The least efficient REE in the observed years were in 1999 and 1996 where almost all of the states were inefficient except for Perak and Sabah (1996) and Pahang and Johor (1999). The lowest REE scores were achieved by Pahang in 1996 that is $43.8 \%$ while the least efficient states were Pahang and Selangor where both of the states achieved 10 inefficiency scores over the years. The most efficient state in REE is Johor where all of the REE scores were greater or equal to 1 with an exception in 1996.

The most efficient year for ENVTECH in brackish-water cages was in 2003 and 2012. The least efficient index was recorded in Sabah in 2010 where $22.6 \%$ of ENVTECH was regressed in their production. The highest efficiency score of ENVTECH was also achieved by Sabah with $29 \%$ progress in technology and innovation in 2009. The least efficient technical progress for the states was observed in Sarawak where 12 out of 20 scores were inefficient. The most efficient state in the technical progress was observed in Perak where 12 out of 20 observations were efficient. These average results reflected that environmental technical change is the main factor behind the improvement of environmental performance index in pond production while the relative eco-efficiency is the major influence factor on environmental performance index in cage aquaculture.

\subsection{Annual means summary of EPI in Malaysian aquaculture}

Based on the annual means of EPI and the components of REE and ENVTECH results in Figure 3, the efficient REE and ENVTECH have influenced the efficiency of EPIs in Malaysian brackish-water ponds in 1994, 1995, 1998, 2000, 2001, 2010, and 2012 whereas the inefficiency of both components affected the EPI in 1996 and 2013. The technical progress is the dominant component in determining efficient EPI's in pond activities except for the year 1999 and 2003.

Compared to pond activities, the dominant role of efficiency component was from REE in determining the efficient EPI in brackish-water cages. Over the years, the REE component dominantly affects the EPI in cage activities. Only 8 out of 20 observation scores showed that technical progress led to inefficient EPI's. With reference to REE results, climate variability over the years have influenced inefficient EPI's of brackish-water cage aquaculture in Malaysia 
in $1994,1996,1999,2001,2002,2007,2010,2011$, and 2012. The regression of technical aspects or innovation in aquaculture activities has caused inefficient EPI results in 2002, 2010, and 2011. The inefficient scores of both REE and ENVTECH have caused inefficient scores to brackish-water cages in 1999 and 2001.

Figure 3: Annual changes in environmental performance and its components of brackish-water ponds and cages, 1993 to 20133

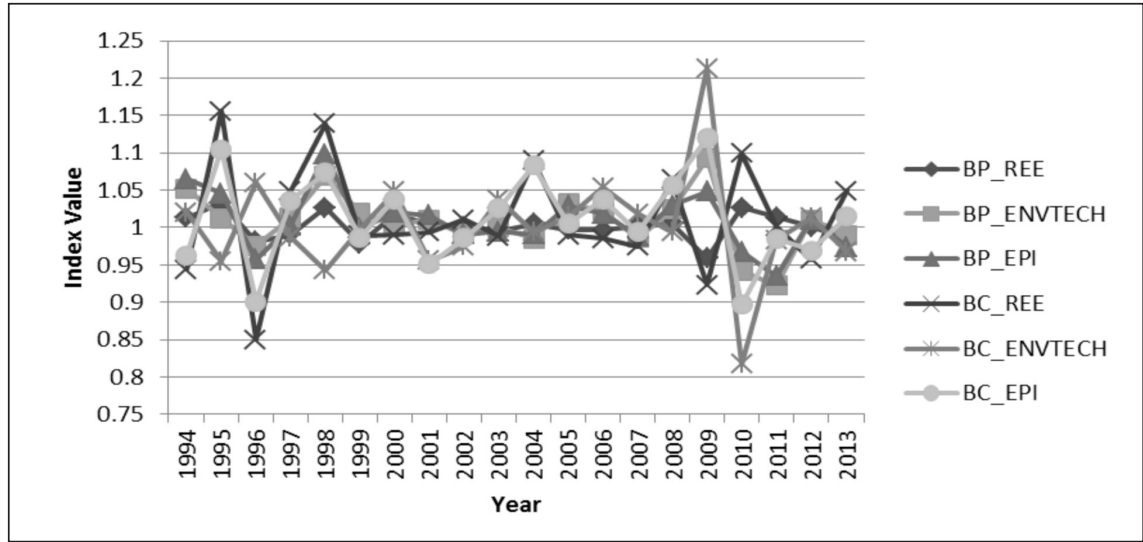

Notes: $\mathrm{BP}=$ brackish-water ponds; $\mathrm{BC}=$ brackish-water cages; $\mathrm{REE}=$ relative ecoefficiency change; ENVTECH = environmental technical change; EPI = environmental performance index.

\subsection{EPI status of the states}

Table 2 shows the decomposition of EPI components with REE and ENVTECH changes with respect to the states. In brackish-water pond aquaculture production, the performance of the states by means of environmental index and its components showed that the ENVTECH change in all the states suggested a strong relationship with the improvements in aquaculture environmental performance. Besides, both REE and ENVTECH change in Perak, Pahang, and Sabah influenced efficient EPI of the states. In contrast, Johor and Sarawak are inefficient in their REE change. However, these results did not influence the decrease in environmental performance. The results verified that ENVTECH change has a strong relationship with the improvements in aquaculture environmental performance in pond aquaculture activities. Based on the results of ENVTECH change, all the states with an exception of Selangor are efficient in environmental performance. The most efficient state in environmental performance is Pahang with a $1.7 \%$ score increase. This increment has dominantly influenced the $0.4 \%$ increment in environmental technical change and $1.3 \%$ of relative eco-efficiency change. The least efficient result was achieved by Selangor with a small decrement of $0.3 \%$ in EPI. This environmental performance index fell due to the $0.2 \%$ decrease in REE and $0.1 \%$ in ENVTECH. The results indicated that the enhancement of technical progress and innovation in aquaculture would be able to help lessen the climate change risks or pressure as shown in Johor and Sarawak. 
Table 2: Environmental performance change and its components, 1993-2013

\begin{tabular}{|c|c|c|c|c|c|c|}
\hline \multirow{3}{*}{ State } & \multicolumn{3}{|c|}{ Brackish-water ponds } & \multicolumn{3}{|c|}{ Brackish-water cages } \\
\hline & \multicolumn{3}{|c|}{ Average value } & \multicolumn{3}{|c|}{ Average value } \\
\hline & REE & ENVTECH & EPI & REE & ENVTECH & EPI \\
\hline Perak & 1.000 & 1.013 & 1.013 & 1.000 & 1.009 & 1.009 \\
\hline Pahang & 1.013 & 1.004 & 1.017 & 1.031 & 0.991 & 1.022 \\
\hline Selangor & 0.998 & 0.999 & 0.997 & 0.999 & 0.999 & 0.998 \\
\hline Johor & 0.998 & 1.006 & 1.004 & 1.003 & 1.000 & 1.003 \\
\hline Sabah & 1.001 & 1.010 & 1.011 & 1.000 & 1.007 & 1.007 \\
\hline Sarawak & 0.998 & 1.011 & 1.009 & 1.026 & 0.994 & 1.020 \\
\hline Mean & 1.001 & 1.007 & 1.008 & 1.010 & 1.000 & 1.010 \\
\hline
\end{tabular}

Based on the brackish-water aquaculture cages, Selangor also showed inefficient EPI for the entire observed years due to inefficient REE and ENVTECH compositions. The results also indicated that since the aquaculture cages are conducted in open water with limited technical usage, the enhancement of technology progress is not a critical factor in influencing efficient EPI's in Pahang and Sarawak. However, climate variability is still tolerable and able to provide good environment for cage aquaculture in said states.

In brackish-water cage systems, environmental performance index for Perak and Sabah were dominantly influenced by ENVTECH changes where the environmental performance index showed similar value with the relative eco-efficiency change. Nevertheless, the contribution of REE to EPI efficiency is significant to Pahang and Sarawak. The REE scores for all states are efficient except for Selangor that needed a $0.1 \%$ increment to achieve efficiency level. The ENVTECH scores for all states were efficient except for Pahang, Selangor, and Sarawak. The results verified that the states need to improve and increase their ENVTECH about $0.9 \%$ for Pahang, $0.1 \%$ for Selangor and $0.6 \%$ for Sarawak, in order to achieve efficiency in their environmental index. The most environmental efficient state in cage activities is Pahang with a $2.2 \%$ increase in EPI. Similarly, as in ponds activities, Selangor is the least efficient state and needs to improve by $0.2 \%$ in order to achieve efficiency. Overall, the EPI change for all states from 1993 to 2013 and their component scores showed that aspects of technical and innovation progress were lacking in the cage activities in Malaysia. With the increasing pattern of climate variability, entrepreneurs might be vulnerable due to the lack of support in adapting to the risks. Due to the limitation in the technical supports, this aquaculture system is dominantly dependent on the condition of the climate. The entrepreneurs have to adapt to the risks by adjusting to the time of production based on the previous year's weather experience.

Under the climate change risks and challenges, environmental technical efficiency component was important to promote efficient aquaculture farms. The technology usage in fish breeding and aquaculture practice will allow the increase of aquaculture activities efficiency in producing quality fishes and resist climate variability and risks. However, technology application was applied highly or only limited to pond aquaculture activities. This is because cage activities are operated in natural environments or fish ecology. Hence, good management of aquaculture practice especially in feeding process will be more helpful in terms of producing high volumes of fish production and reducing the negative effects such as global emissions of aquaculture wastes resulting in environmental degradation. Thus, experienced workers are 
needed in managing the ponds and cages in order to support the farm management efficiently. The increasing cost of farm inputs such as fish feeds and chemical fertilizers had pushed the farmers to low-scale production farms in finding alternative ways of managing their farms with a more sensible cost. Some of the traditional ways of aquaculture practices are still in use and even offer lower costs in conserving production from diseases and other environmental threats, which are also more environmental friendly.

The environmental performance index results of both pond and cage aquaculture showed that Pahang is the best and most efficient in environmental performance whereas Selangor is the least efficient among the states. This result verified that Selangor is more vulnerable to climate change risks as compared to Pahang. Pollution and coastal erosion may be the reasons that contributed to environmental degradation, which caused losses to the aquaculture sector in Selangor as there are rapid growths of other economic sectors in the state. Meanwhile, the highest growth of Aquaculture Industrial Zones in these states had facilitated a good infrastructure for the sustainable production of aquaculture activities that are able to adapt to the climate risks.

\section{CONCLUSIONS}

This study has presented the effects of climate change as environmental pressures on brackishwater aquaculture production through the application of a new dynamic environmental performance analysis. This study has been carried out to gain information and understandings of the risks associated with climate change that affects the efficiency of the aquaculture sector. This study has also demonstrated the significant roles of the components of relative ecoefficiency changes and environmental technical changes on the directions of environmental performance of aquaculture production. These components have helped in highlighting the critical factors that influence the efficiency of aquaculture farms in Malaysia. Generally, the increasing use of aquaculture technologies farm practices may support and boost aquaculture productions. Besides, well-managed farm resources such as capital, labor, and other inputs ensured effective and productive aquaculture productions. Furthermore, the Malmquist DEA results have indirectly depicted the vulnerability level or the index of the states' aquaculture activities due to climate change pressure.

The environmental performance index scores and its components have highlighted the important factors that need to be improved in order to increase the performance of production and to cope with the climate change risks. More research and technology invention for cages activities are needed since the traditional practices are still being applied widely in this system. Meanwhile, for pond activities, utilization of a farm's resources will help to increase the volume of cage production. Apart from creating the adaptation strategy, the focus on mitigating the climate change risks due to the effects of aquaculture production is important. In the long run of socio-economic planning, these results may help capture the effective livelihood strategies of farms such that to increase the quality of life of low-income farmers. However, the results also showed limitations of the findings where in-depth studies are needed to focus on information, perception and feedbacks from the farmers towards climate change risks and their capability to cope with the risk. Hence, these findings suggest that various planned adaptation options must be taken by the local government together with more autonomous adaptation options and practices among the farmers will be helpful in mitigating and adapting to climate changes. 


\section{ACKNOWLEDGEMENT}

The authors would like to thank the State Planning Unit, Sarawak for permission do research, the Inland Fisheries Division, Department of Agriculture, Sarawak, the Department of Marine Fisheries, Sarawak and Natural Resources \& Environmental Board, Sarawak for the assistance in data collection and University of Malaya and University of Malaysia Sarawak for providing the research financial supports.

\section{REFERENCE}

Anon. (2003). Annual Fisheries Statistics (Volume 1). Malaysia: Department of Fisheries Malaysia, Ministry of Agriculture and Afro-Based Industry.

Asian Development Bank [ADB]. (2009). The economics of climate change in Southeast Asia: A regional review. Philippines: Asian Development Bank.

Badjeck, M. C., Allison, E. H., Halls, A. S., \& Dulvy, N. K. (2010). Impacts of climate variability and change on fishery-based livelihoods. Marine policy, 34(3), 375-383.

Baharuddin, M. K. (2007). Climate Change - Its effects on the agricultural sector in Malaysia. Paper presented at National Seminar on Socio-Economic Impacts of Extreme Weather and Climate Change, 21-22 June, Malaysia.

Baran, E., Schwartz, N., \& Kura, Y. (2009). Climate change and fisheries: Vulnerability and adaptation in Cambodia (Issue brief no, 2008). Penang, Malaysia: The WorldFish Center.

Beach, R. H., \& Viator, C. L. (2008). The economics of aquaculture insurance: an overview of the U.S. Pilot Insurance Program for Cultivated Clams. Aquaculture Economics and Management, 12(1), 25-38.

Brander, K. M. (2007). Global fish production and climate change. Proceedings of the National Academy of Sciences, USA, 104(50), 19709 - 19714. doi: 10.1073/pnas.0702059104

Coelli, T. (1996). A guide to DEAP version 2.1: A data development analysis (computer) program. Australia: Centre for Efficiency and Productivity Analysis, University of New England.

De Silva, S. (2007). Meeting the demands and challenges of globalization of trade in aquaculture: The role of a regional Inter-governmental body. Globalisation and Fisheries Proceedings of an OECD-FAO Workshop, France, 229-240.

De Silva, S. S., \& Soto, D. (2009). Climate change and aquaculture: Potential impacts, adaptation and mitigation. In K. Cochrane, C. De Young, D. Soto, \& T. Bahri (Eds.), Climate change implications for fisheries and Aquaculture (pp. 151-212). Rome: Food and Agriculture Organization of the United Nations [FAO].

Department of Statistics [DOS]. (2011). Selected indicator for agriculture, crops and livestock 2006-2010. Putrajaya: Depatment of Statistics, Malaysia. 
Dupont, D., Grafton, R., Kirley, J., \& Squires, D. (2002). Capacity utilization measures and excess capacity in multi-product privatized fisheries. Resource and Energy Economics, 24(3), 193-210.

Edwards, P. (2000). Aquaculture, poverty impacts and livelihoods. Natural Resource Perspective, 56(8), 1- 4.

Farabi, S. S. J. (2009, June 15). Bersedia hadapi El Nino. Utusan Malaysia. Retrieved March 15, 2010, from http://www.utusan.com.my.

Fare, R., Grosskopf, S., Norris, M., \& Zhang, Z. (1994). Productivity growth, technical progress and efficiency change in industrialized countries. American Economic Review, 84(1), 66-83.

Ficke, A. D., Myrick, C. A., \& Hansen, L. J. (2007). Potential impacts of global climate change on freshwater fisheries. Reviews in Fish Biology and Fisheries, 17(4), 581-613.

Flaherty, M., Vandergeest, P., \& Miller, P. (1999). Rice paddy or shrimp pond: tough decisions in rural Thailand. World Development, 27(12), 2045-2060.

Food and Agricultural Organization [FAO]. (2014). The state of world fisheries and aquaculture 2014: Opportunities and challenges. Rome: Food and Agriculture Organization of the United Nations.

Gomez-Limon, J. A., Picazo-Tadeo, A. J., \& Reig-Martinez, E. (2012). Eco-efficiency assessment of olive farms in Andalusia. Land Use Policy, 29(2), 395-406.

Hambal, H., Arshad, M. A., \& Yahaya, S. (1994). Environmental issues of aquaculture development in Malaysia. Malaysia: Fisheries Research Institute, Department of Fisheries.

Handisyde, N. T., Ross, L. G., Badjeck, M. C., \& Allison, E. H. (2006). The effects of climate change on world aquaculture: A global perspective (Final technical report DFID). UK: Aquaculture and Fish Genetics Research Program, Stirling Institute of Aquaculture.

Heltberg, R., Siegel, P. B., \& Jorgensen, S. L. (2009). Addressing human vulnerability to climate change: Toward a 'no-regrets' approach. Global Environmental Change, 19(1), 89-99.

Hoang, V., \& Coelli, T. (2011). Measurement of agriculture total factor productivity growth incorporating environmental factors: A nutrient balance approach. Journal of Environmental Economics and Management, 62(3), 462-474.

Howden, S. M., Soussana, J. F., Tubiello, F. N., Chhetri, N., Dunlop, M., \& Meinke, H. (2007). Adapting agriculture to climate change. Proceedings of the National Academy of Sciences, USA, 104 (50), 19691-19696. doi: 10.1073/pnas.0702059104.

Huppes, D., \& Ishikawa, M. (2005). A framework for quantified eco-efficiency analysis. Journal of Industrial Ecology, 9(4), 25 - 41. 
Idris, K., Azman, A., D’Silva, J. L., Man, N., \& Shaffril, H. A. M. (2014). Environmental challenges on aquaculture rearing in Malaysia: The views of brackish-water cage entrepreneurs in Malaysia. Life Science Journal, 11(7), 509-513.

Kamaruddin, R., \& Siwar, C. (2008). Sustainable aquaculture for poverty alleviation and food security in Asia. In C. Siwar, R. Ghazali, M. E. Hossain, \& A. M. Abdulai (Eds.), Linking rural poverty and environment: Governance and sustainable development policies (pp. 322-338). Selangor: Institute for Environment and Development (LESTARI), Universiti Kebangsaan Malaysia.

Kamaruddin, R., Siwar, C., Jaarfar, A. H., \& Mokhtar, M. (2008). The sustainability of aquaculture practices in Malaysia. In C. Siwar, R. Ghazali, M. E. Hossain, \& A. M. Abdulai (Eds.), Linking rural poverty and environment: Governance and sustainable development policies (pp. 275-290). Selangor: Institute for Environment and Development (LESTARI), Universiti Kebangsaan Malaysia.

Kelly, P. M. \& Adger, W. N. (1999). Assessing vulnerability to climate change and facilitating adaptation (Centre for Social and Economic Research on the Global Environment Working Paper GEC 99-07). Norwich: University of East Anglia.

Kortelainen, M. (2008). Dynamic environmental performance analysis: A Malmquist index approach. Ecological Economics, 64(4), 701-715.

Kuosmanen, T., \& Kortelainen, M. (2005). Measuring eco-efficiency of production with data envelopment analysis. Journal of Industrial Ecology, 9(4), 59 - 72.

Lansink, A. O. \& Wall, A. (2014). Frontier models for evaluating environmental efficiency: An overview. Economic and Business Letters, 3(1), 43-50.

Lungren, R., Staples, D., Funge-Smith, S., \& Clausen, J. (2006). Status and Potential of Fisheries and Aquaculture in Asia and the Pacific 2006 (APFIC/FAO RAP Publication 2006/22). Bangkok: FAO Regional Office for Asia and the Pacific.

Lymer, D. Funge-Smith, S, Clausen, J., \& Miao, W. (2008). Status and potential of fisheries and aquaculture in Asia and the Pacific 2008 (APFIC/FAO RAP Publication 2008/15). Bangkok: FAO Regional Office for Asia and the Pacific.

Magawata, I., \& Ipinjolu, J. K. (2014). Climate change: Mitigation and adaptation strategies in fisheries and aquaculture in Nigeria. Journal of Fisheries and Aquatic Science, 9(4), 257-261.

Malaysia Productivity Corporation [MPC]. (2014). Productivity Report 2013/2014. Malaysia: Malaysia Productivity Corporation.

Ministry of Finance [MOF]. (2003). Economics report 2003. Kuala Lumpur: Ministry of Finance Malaysia.

Ministry of Finance [MOF]. (2011). Economic report 2011. Kuala Lumpur: Ministry of Finance Malaysia. 
Miola,A. \& Simonet, C. (2014). Concepts and metrics for climate change risk and development: Towards an index for climate resilience development (JRC science and policy reports EUR 26587EN). Italy: European Commission Joint Research Centre.

Mohd. S., M., Alias, B., \& Daud, D. (2006). GIS analysis for flood hazard mapping. Case study: Segamat Johor, West Malaysia. Seminar Nasional GIS 2006.

Mustapha, N. H. N., Aziz, A. A., \& Hashim, N. M. H. (2013). Technical efficiency in aquaculture industry using Data Envelopment Analysis (DEA) window: Evidences from Malaysia. Journal of Sustainability Science and Management, 8(2), 137-149.

Nishimizu, M., \& Page, J. M. (1982). Total productivity growth, technological change and technical efficiency change. Economic Journal, 92(368), 920 - 936.

Oguntuga, O. A., Adesina, B. T., \& Akinwole, A. O. (2009). The challenges of climate change in fisheries and aquaculture: Possible adaptation measures in Nigeria. Capacity Development and Career Prospects in Conservation Science, 56.

Oliveira, M. M., Gaspar, M. B., Paixão, J. P., \& Camanho, A. S. (2009). Productivity change of the artisanal fishing fleet in Portugal: A Malmquist index analysis. Fisheries Research, 95(2), 189-197.

Othman, M. F. (2006). Recent report on coastal / marine aquaculture status in Malaysia. Malaysia: Department of Fisheries Malaysia.

Pascoe, S., \& Herrero, I., (2004). Estimation of composite fish stock index using data envelopment analysis. Fisheries Research, 69(1), 91-105. Doi: 10.1016/j.fishres.2004.03.003

Picazo-Tadeo, A. J., \& Prior, D. (2009). Environmental externalities and efficiency measurement. Journal of Environmental Management, 90(11), 3332-3339.

Picazo-Tadeo, A. J., Gomez-Limon, J. A., \& Reig-Martinez, E. (2011). Assessing farming eco-efficiency: A Data Envelopment Analysis Approach. Journal of Environmental Management, 92(4), 1154 - 1164. doi: 10.1016/j.jenvman.2010.11.025

Ramli, N. A. (2013). Modeling undesirable factors in efficiency evaluation with an application to the Malaysian manufacturing sector (Unpublished doctoral dissertation). University of Malaya, Kuala Lumpur.

Schjolden, A. (2004). Towards assessing socioeconomic impacts of climate change in Norway: Sensitivity in the primary sectors: fisheries, agriculture, agriculture and forestry. Oslo, Norway: Center for International Climate and Environmental Research.

Serrao, A. (2008, July). Measuring eco-efficiency of agricultural activity in European countries: A Malmquist Index Approach. Paper presented at the American Agricultural Economics Association Annual Meeting, Orlando, FL.

Siwar, C., Alam, M. M., Murad, M. W., \& Al-Amin, A. Q. (2009). Impacts of climate change on agricultural sustainability and poverty in Malaysia. Proceedings of the 10th International Business Research Conference, Dubai, UAE, 1-15. 
Sugiyama, S., Staples, D., \& Funge-Smith, S. (2004). Status and potential of fisheries and aquaculture in Asia and the Pacific (APFIC/FAO RAP Publication 2004/25) Bangkok: FAO Regional Office for Asia and the Pacific).

Sulit, V. T., Aldon, M. E. T., Tendencia, I. T., Ortiz, A. M. J., Alayon, S. B., \& Ledesma, A. S. (2005). Regional Technical Consultation on the Aquaculture of P. vannamei and other exotic shrims in Southeast Asia. Tigbauan, Iloilo, Philippines: SEAFDEC Aquaculture Department.

Sulong, T. (2008, December 6). 100 penternak ikan rugi RM1 juta. Utusan Malaysia. Retrieved March 15, 2010, from http://www.utusan.com.my.

Sungan, S. (2002). Aquaculture and water quality. Sarawak Development Journal, 5(2), 95-115.

Tan, C. K. (1998). Overview of aquaculture in Malaysia. In G. Nagajraj, \& T. Singh (Eds.), Aquaculture practices in Malaysia. Malaysia: Malaysian Fisheries Society.

Thomas, J. M., \& Callan, S. J. (2007). Environmental Economics: Applications, Policy and Theory. United States: Thompson South-Western.

Tingley, D., Pascoe, S., \& Coglan, L. (2005). Factors affecting technical efficiency in fisheries: Stochastic production frontier versus Data Envelopment Analysis approaches. Fisheries Research, 73(3), 363-376.

Tingley, D., Pascoe, S., \& Mardle, S. (2003). Estimating capacity utilization in multi-purpose, multi-métier fisheries. Fisheries Research, 63(1), 121-134.

Tisdell, C. A., \& Leung, P. S. (1999). Overview of environmental and sustainability issues in aquaculture. Aquaculture Economics and Management, 3(1), 1-5.

Vazquez-Rowe, I. \& Tyedmers, P. (2013). Identifying the importance of "skipper effect" within source of measured inefficiency in fisheries through data envelopment analysis (DEA). Marine Policy, 38(1), 387 - 396. doi: 10.1016/j.marpol.2012.05.018

Westlund, L., Poulain, F., Bage, H., \& Anrooy, R. V. (2007). Disaster Response and Risk Management in the Fisheries Sector (FAO Fisheries Technical Paper No, 479). Rome: Food and Agriculture Organization of the United Nations.

World Bank. (2010). World Development Report 2010: Development and Climate Change. New York: The World Bank.

WorldFish. (2009). Climate Change: Research to meet the challenges facing fisheries and aquaculture (Issues Brief No, 1915). Penang, Malaysia: The WorldFish Center.

Ytrestoyl, T., Aas, T. S., Berge, G. M., Hatken, B., Sorensen, M., Ruyter, B., Thomassen, M., Hognes, E. S., Ziegler, F., Sund, V., \& Asgard, T. (2011). Resource utilization and ecoefficiency of Norwegian salmon farming in 2010 (Report 53/2011). Norway: Nofima AS. 